\title{
VELOCITY PROFILE MODELING FOR NON-ISOTHERMAL FLOWS INSIDE A CIRCULAR TUBE
}

\author{
J. A. Gutierrez ${ }^{\text {a }}$ ABSTRACT \\ A. A. Mendiburu ${ }^{a}$, \\ I. Ávila ${ }^{a}$, \\ and Edgar Paz Peréz \\ This research proposes a new method to establish the velocity field and the \\ dimensionless velocity profile for Newtonian and non-Newtonian flows \\ inside a circular tube. Several studies developed regarding different fluid \\ types (such as potency law fluid, Bingham and Herschel-Bulkley, among \\ others) observed that a rational or irrational polynomial was used for the \\ dependent velocity field variable. Thus, a rational polynomial was \\ established as a starting point for this research as the dependent velocity \\ field variable. Dimensionless velocity profiles obtained from the proposed \\ fluid-dynamics model were experimentally compared only with \\ dimensionless velocity profiles for non-isothermal Newtonian flows of \\ glycerol, in cooling as well as heating. On the other hand, it was possible to \\ calculate that RMS errors found using relative dimensionless velocity data \\ obtained from the proposed fluid-dynamics model creates very small errors, \\ which are comparable to RMS errors found using data obtained from \\ application of a numerical method. Finally, the proposed fluid-dynamics \\ model was validated with a dimensionless velocity profile obtained from the \\ flow of a cooling process, resulting in the validity of the proposed model. \\ Received: July 9, 2017 \\ Revised: November 1, 2017 \\ Accepted: December 23, 2017 \\ Keywords: rheology, velocity profile, non-isothermal fluids, circular tube
}

\section{NOMENCLATURE}

$\mathrm{A}_{\mathrm{T}} \quad$ Cross-sectional area to the pipe, $\mathrm{m}^{2}$

$\mathrm{e}_{\mathrm{r}} \quad$ Radial parameter

$\mathrm{e}_{\theta} \quad$ Angular parameter

$\mathrm{e}_{\mathrm{x}} \quad$ Positional parameter

$\mathrm{e}_{\mathrm{t}} \quad$ Thermodynamic parameter

$\mathrm{e}_{\mathrm{T}} \quad$ Time, $\mathrm{h}$

$\mathrm{F}_{\mathrm{obj}} \quad$ Convex objective function

Q Quantity giving the deviation from isoviscous behaviour

$\mathrm{r} \quad$ Radial coordinate, $\mathrm{m}$

$\mathrm{R}$ Tube radius, $\mathrm{m}$

$\mathrm{S}_{\mathrm{T}} \quad$ Transversal section

$\mathrm{V}^{\mathrm{x}} \quad$ Velocity field, $\mathrm{m} / \mathrm{s}$

$\mathrm{V}_{\text {shaft }}^{\mathrm{x}}$ Velocity on the pipe shaft, $\mathrm{m} / \mathrm{s}$

$\mathrm{V}_{\text {rel }}^{\mathrm{x}} \quad$ Relative dimensionless velocity

$\mathrm{V}_{\mathrm{m}}^{\mathrm{x}} \quad$ Average velocity, $\mathrm{m} / \mathrm{s}$

$\mathrm{V}_{\text {mod }}^{\mathrm{x}}$ Velocity of model

\section{Greek symbols}

$\alpha \quad$ Relative velocity coefficient

$\rho \quad$ Density, $\mathrm{kg} / \mathrm{m}^{3}$

\section{Subscripts}

exp Experimental

\section{Superscripts}

$\mathrm{x} \quad$ Axial direction to the tube

\section{INTRODUCTION}

Research regarding the rheology of Newtonian and non-Newtonian flows inside channels of different transversal sections and circular section tubes is currently very developed (Choi et al., 2016). There is a certain assurance for the study of Newtonian flows. However, researches for non-Newtonian flows are still being developed. A rheological model is initially chose for study of non-Newtonian flows (Irgens, 2014), with a starting point being the relation of shearing tension to shearing rate (velocity profile), for different rheological models, such as potency law, Bingham, Herschel-Bulkley, among others (LópezCarranza, Jenny, Nouar, 2012; Peixinho et al., 2005). All of these models are restricted to border conditions of flow inside the channel or tube. Maybe the most common rheological model is the potency law model (Güzel, Frigaard, Martinez, 2009; Hanley, Cronin, Byrne, 2013), and the general model would be the Herschel-Bulkley (Ancey, Bates, 2017; Bentrad et al., 2017). A consequence of choosing a good rheological model is a good agreement between the profiles for experimental velocity and analytical or simulated velocity. The Dutch engineer Pieter Barteld Kwant was one of the first researchers to work with non-Newtonian flows. In the theoretical research by 
Kwant, Zwaneveld and Dijkstra (Kwant, Zwaneveld, Dijkstra, 1973b) for non-isothermal flows, the potency law model was employed to study velocity profiles using two methodologies: an approximate method (includes the mass conservation equation and momentum equation) and a numerical method (includes previous equations, plus the energy equation). Later on, research conducted by Kwant, Fierens and Van Der Lee (Kwant, Fierens, Van Der Lee, 1973a) produced experimental results to validate theoretical results from the work of Kwant, Zwaneveld and Dijkstra (Kwant, Zwaneveld, Dijkstra, 1973b).

Normally, several research studies use the computer fluid dynamics (CFD) for flow modeling (Martins et al., 2014, 2016; Wang, Zhang, Wang, 2013). The CFD model employs border conditions, the mass conservation equation, the momentum equation, among others. Advancements regarding the study of non-Newtonian flows is diverse, such as the study of the tube inclination effect over the removal dynamics of a viscous-plastic fluid by a Newtonian fluid (Alba, Frigaard, 2016), the behavior of a Herschel-Bulkley fluid layer when it is suddenly inclined and subjected to gravitational forces (Ancey, Bates, 2017), the effects of the velocity profile in the entrance of a cooling channel over flow (Kim et al., 2016), the study of the velocity profiles (before and after a porous zone) of a turbulent flow in a straight channel (Choi et al., 2016), or the thermal conditioning in the tube wall (Bertsche, Knipper, Wetzel, 2016; Tu et al., 2015; Weigand, Abdelmoula, 2014).

Wang et al. (2017) performed one interesting study, in which a rheological model was not used for modeling the velocity profile of a heterogeneous flow. These authors established a rational polynomial in the variable depending on the velocity field in order to model the velocity profile. Such rational polynomial has 10 terms, which are based on space coordinates, tube diameter, particle size, ice fraction, and average flow velocity. The idea to establish a rational polynomial to a depending variable for the velocity field was also employed in another study (Amaro, Hernández, Olivencia, 2015).

This current research consists on modeling dimensionless velocity profiles for laminar Newtonian flows in which the tube wall temperature was constant for each experiment. In order to do that, a generalization was employed regarding the polynomial expression proposed in the previously mentioned research (Amaro, Hernández, Olivencia, 2015) for the dependent velocity field variable. This polynomial expression was restricted by appropriate border conditions as those used in previous researches that used rheological models.

\section{MATERIALS AND METHODS}

In order to define the velocity field dependent variable (considering only the velocity axial component) of a flow for any fluid inside a circular section tube, a rational polynomial was employed, which was much simpler than the one employed by Wang et al. (2017).

$$
\begin{aligned}
& \mathrm{V}^{\mathrm{x}}\left(\mathrm{e}_{\mathrm{r}}, \mathrm{e}_{\theta}, \mathrm{e}_{\mathrm{x}}, \mathrm{e}_{\mathrm{t}_{1}}, \mathrm{e}_{\mathrm{t}_{2}}, \ldots, \mathrm{e}_{\mathrm{t}_{\mathrm{j}}}, \mathrm{e}_{\mathrm{T}}\right)= \\
& \sum_{\mathrm{i}=1}^{\mathrm{n}} \mathrm{V}_{\mathrm{i}}^{\mathrm{x}}\left(\mathrm{e}_{\theta}, \mathrm{e}_{\mathrm{x}}, \mathrm{e}_{\mathrm{t}_{1}}, \mathrm{e}_{\mathrm{t}_{2}}, \ldots, \mathrm{e}_{\mathrm{t}_{\mathrm{j}}}, \mathrm{e}_{\mathrm{T}}\right) \mathrm{e}_{\mathrm{r}}^{\mathrm{i}}+ \\
& \mathrm{V}_{\text {shaft }}^{\mathrm{x}}\left(\mathrm{e}_{\mathrm{x}}, \mathrm{e}_{\mathrm{t}_{1}}, \mathrm{e}_{\mathrm{t}_{2}}, \ldots, \mathrm{e}_{\mathrm{t}_{\mathrm{j}}}, \mathrm{e}_{\mathrm{T}}\right)
\end{aligned}
$$

The velocity field dependent variable is defined on Eq. (1), where $e_{r}, e_{\theta}$ and $e_{x}$, are the independent variables, which depends on internal radius, the angle, and position regarding the beginning of the tube, respectively. They are independent variables that relate cylindrical coordinates. The $e_{t_{j}}$ independent variable is an average thermodynamic parameter (or a parameter that relates a thermodynamic property in an implicit manner) evaluated in a certain transversal section $\left(\mathrm{S}_{\mathrm{T}}\right)$ to the tube or it is characteristic for all the tube (for example: constant temperature or constant heat flow). Finally, the $\mathrm{e}_{\mathrm{T}}$ independent variable is the time variable. Some considerations were formulated, which are presented as follows:

i) The tube through which the fluid flows is internally smooth and it is placed on a horizontal position.

ii) The flow under study is in complete hydrodynamic development.

iii) A value of $n=3$ was employed to evaluate the velocity field dependent variable.

iv) The flow regimen is stationary.

v) The velocity field is independent from the $e_{\theta}$ variable.

vi) Due to denotative simplicity, only one thermodynamic parameter was employed and named as $e_{t}$ (but some change in such consideration can be modified in future studies, without any problem).

vii)The following notations were established by denotative simplicity:

$$
\begin{gathered}
\left(e_{r}, e_{x}, e_{t}\right)=\left(e_{r, x, t}\right) \\
\left(e_{x}, e_{t}\right)=\left(e_{x, t}\right)
\end{gathered}
$$

The internal radius and the tube transversal circle area are named as $\mathrm{R}$ and $\mathrm{A}_{\mathrm{T}}$, respectively.

$$
\mathrm{e}_{\mathrm{r}}=\frac{\mathrm{r}}{\mathrm{R}}
$$


The $e_{r}$ independent variable was defined in Eq. (4), as $0 \leq r \leq R$. Definition of $e_{x}$ and $e_{t}$ independent variables will depend on the study which will be chosen as a reference.

It is important to notice that it was not established if the flow regimen is laminar, transitory or turbulent, since it was not defined if the fluid is incompressible due to the dependence of the behavior regarding the thermodynamic parameter along the flow. $D_{r, x, t}$ and $D_{x, t}$ are non-empty sets in which their elements are $\left(\mathrm{e}_{\mathrm{r}, \mathrm{x}, \mathrm{t}}\right)$ and $\left(\mathrm{e}_{\mathrm{x}, \mathrm{t}}\right)$, respectively. The simplified velocity field (by previous considerations) and the flow density $(\rho)$ were established as real functions defined in the $\mathrm{D}_{\mathrm{r}, \mathrm{x}, \mathrm{t}}$ domain.

$$
\begin{aligned}
& V^{x}\left(e_{r, x, t}\right) \\
& =V_{3}^{x}\left(e_{x, t}\right) e_{r}^{3}+V_{2}^{x}\left(e_{x, t}\right) e_{r}^{2} \\
& +V_{1}^{x}\left(e_{x, t}\right) e_{r}+V_{\text {shaft }}^{x}\left(e_{x, t}\right)
\end{aligned}
$$

Equation (5) shows a simplified expression of the velocity field dependent variable.

$$
\begin{array}{r}
\rho_{\mathrm{m}, \mathrm{x}}\left(\mathrm{e}_{\mathrm{x}, \mathrm{t}}\right)=\frac{\int_{\mathrm{S}_{\mathrm{T}}} \rho\left(\mathrm{e}_{\mathrm{r}, \mathrm{x}, \mathrm{t}}\right) \mathrm{V}^{\mathrm{x}}\left(\mathrm{e}_{\mathrm{r}, \mathrm{x}, \mathrm{t}}\right) \mathrm{dA}_{\mathrm{T}}}{\int_{\mathrm{S}_{\mathrm{T}}} \mathrm{V}^{\mathrm{x}}\left(\mathrm{e}_{\mathrm{r}, \mathrm{x}, \mathrm{t}}\right) \mathrm{dA_{T }}} \\
\mathrm{V}_{\mathrm{m}}^{\mathrm{x}}\left(\mathrm{e}_{\mathrm{x}, \mathrm{t}}\right)=\frac{\int_{\mathrm{S}_{\mathrm{T}}} \mathrm{V}^{\mathrm{x}}\left(\mathrm{e}_{\mathrm{r}, \mathrm{x}, \mathrm{t}}\right) \mathrm{dA}_{\mathrm{T}}}{\mathrm{A}_{\mathrm{T}}}
\end{array}
$$

On the other hand, it was necessary to establish flow average density $\left(\rho_{\mathrm{m}, \mathrm{x}}\right)$ and flow average velocity $\left(V_{m}^{x}\right)$ as real functions defined in the $D_{x, t}$ domain. Dependent variables for both functions are defined on Eq. (6) and (7), respectively.

$$
\alpha\left(e_{x, t}\right)=\frac{V_{\text {shaft }}^{\mathrm{x}}\left(e_{x, t}\right)}{V_{m}^{x}\left(e_{x, t}\right)}
$$

A relative velocity coefficient was defined and identified as $\alpha$. It is presented on Eq. (8).

Some conditions were established, which served to restrict the $\mathrm{V}^{\mathrm{x}}\left(\mathrm{e}_{\mathrm{r}, \mathrm{x}, \mathrm{t}}\right)$ dependent variable. These conditions are presented as below:

$$
\begin{gathered}
\left.\frac{\partial \mathrm{V}^{\mathrm{x}}\left(\mathrm{e}_{\mathrm{r}, \mathrm{x}, \mathrm{t}}\right)}{\partial \mathrm{e}_{\mathrm{r}}}\right|_{\mathrm{e}_{\mathrm{r}}=0}=0 \\
\mathrm{~V}^{\mathrm{x}}\left(1, \mathrm{e}_{\mathrm{x}}, \mathrm{e}_{\mathrm{t}}\right)=0
\end{gathered}
$$

$$
\begin{aligned}
\int_{S_{T}} \rho\left(e_{r, x, t}\right) V^{x}\left(e_{r, x, t}\right) d A_{T} & \\
& =\rho_{m, x}\left(e_{x, t}\right) V_{m}^{x}\left(e_{x, t}\right) A_{T}
\end{aligned}
$$

In Eqs. (9) - (11) the conditions of: Condition of maximum velocity in the tube axis, Non-slippery condition in the tube internal wall and Mass conservation condition, respectively, are presented.

$$
\mathrm{V}^{\mathrm{x}}\left(\mathrm{e}_{\mathrm{r}, \mathrm{x}, \mathrm{t}}\right)=\left[\begin{array}{l}
\alpha\left(\mathrm{e}_{\mathrm{x}, \mathrm{t}}\right)\left(5 \mathrm{e}_{\mathrm{r}}^{3}-6 \mathrm{e}_{\mathrm{r}}^{2}+1\right) \\
+10 \mathrm{e}_{\mathrm{r}}^{2}-10 \mathrm{e}_{\mathrm{r}}^{3}
\end{array}\right] \mathrm{V}_{\mathrm{m}}^{\mathrm{x}}\left(\mathrm{e}_{\mathrm{x}, \mathrm{t}}\right)
$$

A final expression for the velocity field dependent variable was obtained by using Eq. (9) (11) to restrict $\mathrm{V}^{\mathrm{x}}\left(\mathrm{e}_{\mathrm{r}, \mathrm{x}, \mathrm{t}}\right)$, and it is presented on Eq. (12).

$$
\mathrm{V}_{\mathrm{rel}}^{\mathrm{x}}\left(\mathrm{e}_{\mathrm{r}, \mathrm{x}, \mathrm{t}}\right)=\frac{\mathrm{V}^{\mathrm{x}}\left(\mathrm{e}_{\mathrm{r}, \mathrm{x}, \mathrm{t}}\right)}{\mathrm{V}_{\mathrm{m}}^{\mathrm{x}}\left(\mathrm{e}_{\mathrm{x}, \mathrm{t}}\right)}
$$

Finally, the expression for relative dimensionless velocity profile $\left(\mathrm{V}_{\text {rel }}^{\mathrm{x}}\right)$ is shown on Eq. (13).

For laminar isothermal Newtonian flows, $\alpha\left(\mathrm{e}_{\mathrm{x}, \mathrm{t}}\right)=2$ is employed, creating a known expression for the velocity dimensionless profile equivalent to $\mathrm{V}_{\mathrm{rel}}^{\mathrm{x}}\left(\mathrm{e}_{\mathrm{r}, \mathrm{x}, \mathrm{t}}\right)=2-2 \mathrm{e}_{\mathrm{r}}^{2}$. The RMS error (root mean square) was employed in order to evaluate the predictability of the relative dimensionless velocity profile regarding research experimental data that might be used (Devore, Berk, 2012).

$$
\mathrm{RMS}=\sqrt{\frac{\sum_{\mathrm{i}=1}^{\mathrm{m}}\left(\mathrm{V}_{\exp _{\mathrm{i}}}^{\mathrm{x}}-\mathrm{V}_{\text {mod }_{\mathrm{i}}}^{\mathrm{x}}\right)^{2}}{\mathrm{~m}}}
$$

The mathematical expression for RMS error, applied in this study, is presented on Eq. (14). Where $\mathrm{m}$ is the number of experimental data and $\mathrm{V}_{\exp }^{\mathrm{x}}$ is the experimental velocity or the experimental relative dimensionless velocity provided by a certain radius. The $\mathrm{V}_{\text {mod }}^{\mathrm{x}}$ velocity is obtained by the proposed model from Eq. (12) or Eq. (13). This depends on data provided by studies used to validate the proposed model. The experimental relative dimensionless velocity was defined as the experimental velocity divided by the average velocity. It is clear that Eq. (12) needs to be used to validate the model, in case experimental velocities are provided.

Thus, the dependent variable can be represented as $\mathrm{V}^{\mathrm{x}}\left(\mathrm{e}_{\mathrm{r}, \mathrm{x}, \mathrm{t}}\right)$ by $\mathrm{V}^{\mathrm{x}}\left(\mathrm{e}_{\mathrm{r}}, \mathrm{V}_{\mathrm{m}}^{\mathrm{x}}\left(\mathrm{e}_{\mathrm{x}, \mathrm{t}}\right), \mathrm{V}_{\text {shaft }}^{\mathrm{x}}\left(\mathrm{e}_{\mathrm{x}, \mathrm{t}}\right)\right)$. Due to denotative simplicity reasons, the dependent variable 
was considered to be $\mathrm{V}^{\mathrm{x}}\left(\mathrm{e}_{\mathrm{r}, \mathrm{x}, \mathrm{t}}\right)$ by $\mathrm{V}^{\mathrm{x}}\left(\mathrm{e}_{\mathrm{r}}, \mathrm{V}_{\mathrm{m}}^{\mathrm{x}}, \mathrm{V}_{\text {shaft }}^{\mathrm{x}}\right)$. For the case in which experimental velocities are provided, a methodology was developed to allow calculation of more suitable velocity values, $V_{m}^{\mathrm{x}}$ and

$$
\mathrm{F}_{\text {obj, }, 1}\left(\mathrm{~V}_{\mathrm{m}}^{\mathrm{x}}, \mathrm{V}_{\text {shaft }}^{\mathrm{x}}\right)=\sum_{\mathrm{i}=1}^{\mathrm{m}}\left[\mathrm{V}_{\text {exp }}^{\mathrm{x}}-\mathrm{V}_{\mathrm{i}}^{\mathrm{x}}\left(\mathrm{V}_{\mathrm{m}}^{\mathrm{x}}, \mathrm{V}_{\text {shaft }}^{\mathrm{x}}\right)\right]^{2}
$$

The corresponding convex objective function was established in Eq. (15). Thus, this objective function has to satisfy the following conditions:

$$
\begin{aligned}
& \frac{\partial \mathrm{F}_{\text {obj, }, 1}\left(\mathrm{~V}_{\mathrm{m}}^{\mathrm{x}}, \mathrm{V}_{\text {shaft }}^{\mathrm{x}}\right)}{\partial \mathrm{V}_{\mathrm{m}}^{\mathrm{x}}}=0 \\
& \frac{\partial \mathrm{F}_{\text {obj, }, 1}\left(\mathrm{~V}_{\mathrm{m}}^{\mathrm{x}}, \mathrm{V}_{\text {shaft }}^{\mathrm{x}}\right)}{\partial \mathrm{V}_{\text {shaft }}^{\mathrm{x}}}=0
\end{aligned}
$$

Once $V_{m}^{x}$ and $V_{\text {shaft }}^{\mathrm{x}}$ velocity values are obtained for different experiments, values for relative velocity coefficient can be calculated $(\alpha)$.

In case experimental relative dimensionless velocities are provided, a similar method to the previous one can be applied, changing the objective function and the conditions of the first derivative.

$$
\mathrm{F}_{\text {obj }, 2}(\alpha)=\sum_{\mathrm{i}=1}^{\mathrm{m}}\left[\mathrm{V}_{\mathrm{exp}_{\mathrm{i}}}^{\mathrm{x}}-\mathrm{V}_{\mathrm{i}}^{\mathrm{x}}(\alpha)\right]^{2}
$$

The corresponding convex objective function was established in Eq. (18). Thus, this objective function has to satisfy the following condition:

$$
\frac{\partial \mathrm{F}_{\mathrm{obj}, 2}(\alpha)}{\partial \alpha}=0
$$

A behavior for the relative velocity coefficient can be established with these methods, for any position and thermal condition in the tube wall under study. An appropriate expression can be attributed to the relative velocity coefficient by using a linear regression model (Kleijnen, 2015).

\section{RESULTS AND DISCUSSION}

In order to validate the proposed fluid-dynamics model, experimental data were employed from Kwant (Kwant, 1971) and Kwant et al. (Kwant, Fierens, Van Der Lee, 1973a), the working fluid being glycerol in both studies. In addition, data regarding relative dimensionless velocities obtained through the numerical method proposed by Kwant et al. (1973b) were compared with experimental relative dimensionless velocities. The of data regarding experimental relative dimensionless velocities and from the numerical solution were derived from scaling velocity profile figures. Kwant et al. (1973a) studied velocity profiles for Newtonian laminar flows in a tube where wall temperature is constant, but different in each experiment that is performed.

Experimental and numerical relative dimensionless velocities are a function of $\mathrm{x}^{+}, \mathrm{Q}$ and $\langle\operatorname{Re}\rangle$ parameters, which are the dimensionless axial position, iso-viscosity standard parameter regarding the flow, and the Reynolds number evaluated at the average flow temperature, respectively. For more references regarding these parameters, the study by Kwant et al. (1973a) can be revised. The current study considered that the positional parameter $\left(\mathrm{x}^{+}\right)$ does not create significant changes in the relative dimensionless velocity profile. This assumption was considered due to the fact that several velocity profiles are not present for the same tube thermal condition. In addition, the Reynolds number $(\langle\operatorname{Re}\rangle)$ was not selected as a thermodynamic parameter since all flows that generate experimental and numerical relative dimensionless velocity data are characterized by a laminar regimen, and also have a Reynolds number in the range of 0.24 to 55 (Kwant, 1971), which was considered very low to produce significant changes in the dimensionless velocity profile.

Due to previous assumptions, the Q thermodynamic parameter was considered the most influential in experiments conducted, since it quantifies heat transference between the flow and the tube, characterizing the heat transfer phenomenon on heating or cooling processes. It is then possible to establish that $\mathrm{e}_{\mathrm{t}}=\mathrm{Q}$. The $\mathrm{Q}$ value is equivalent to zero in case the flow and the tube have the same temperature.

$$
\begin{aligned}
& \mathrm{V}_{\mathrm{rel}}^{\mathrm{X}}\left(\mathrm{e}_{\mathrm{r}}, \mathrm{Q}\right) \\
& =\alpha(\mathrm{Q})\left(5 \mathrm{e}_{\mathrm{r}}^{3}-6 \mathrm{e}_{\mathrm{r}}^{2}+1\right)+10 \mathrm{e}_{\mathrm{r}}^{2}-10 \mathrm{e}_{\mathrm{r}}^{3}
\end{aligned}
$$

The proposed fluid-dynamic model to determine relative dimensionless velocity profiles is presented on Eq. (20). Figure 1 shows the dimensionless velocity profile for the flow of a cooling process with $\mathrm{Q}=-2.06$ (Kwant, 1971). For this case, one $\alpha=3.053$ was determined. The RMS error for data obtained from the proposed method and the numerical method was equivalent to 0.09080 and 0.07382 , respectively.

Figure 2 shows a dimensionless velocity profile for the flow of a heating process with $\mathrm{Q}=1.49$ (Kwant, Fierens, Van Der Lee, 1973a). In this case, one $\alpha=1.577$ was determined. The RMS error for data obtained from the proposed model and the numerical method was equivalent to 0.02269 and 0.04002 , respectively. 


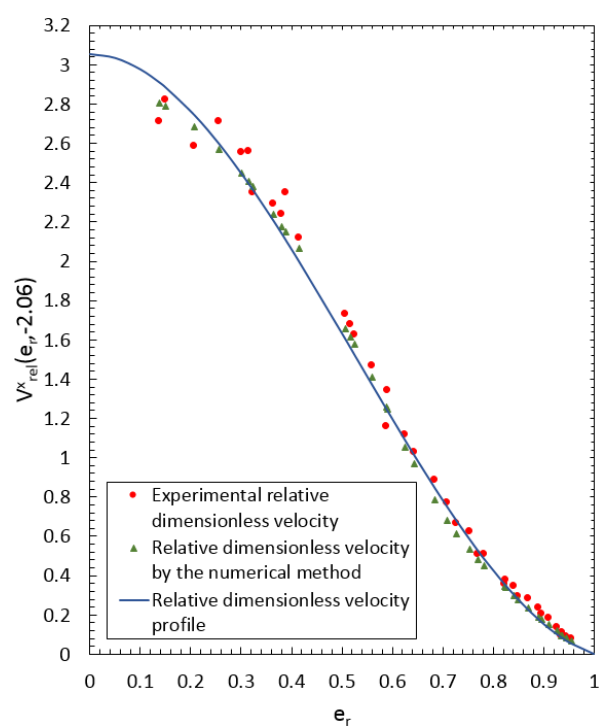

Figure 1. Dimensionless velocity profile for $\mathrm{Q}=-$ 2.06 .

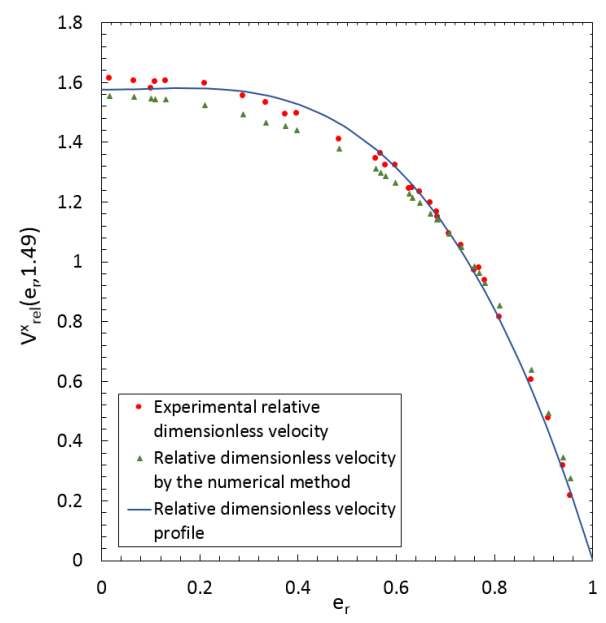

Figure 2. Dimensionless velocity profile for $\mathrm{Q}=1.49$.

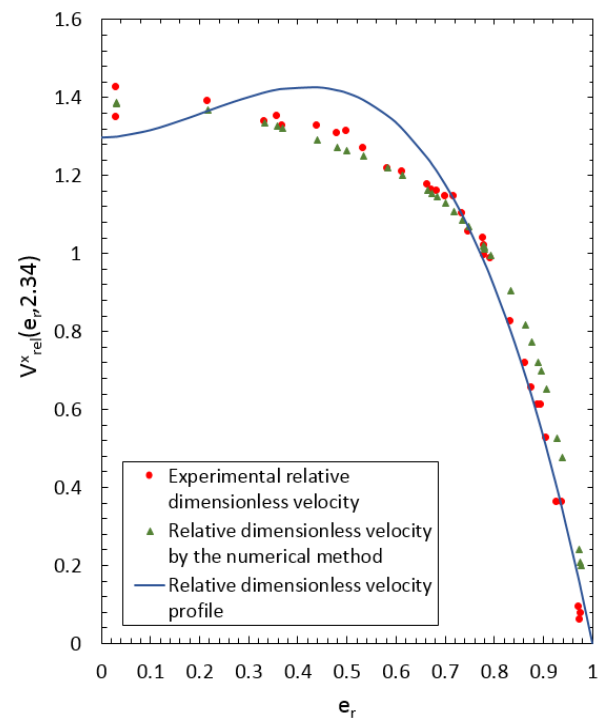

Figure 3. Dimensionless velocity profile for $\mathrm{Q}=2.34$.
Figure 3 shows the dimensionless velocity profile for the flow of a heating process with $\mathrm{Q}=2.34$ (Kwant, 1971). In this case, one $\alpha=1.298$ was determined. The RMS error for data obtained from the proposed model and the numerical method was equivalent to 0.06887 and 0.07249 , respectively.

With different calculated $\alpha$ values and $Q$ values used in previous experiments, a linear regression model was developed with $\alpha=2$ for $Q=0$, in order to calculate the relative velocity coefficient value $(\alpha)$.

$$
\alpha(Q)=0.0432 Q^{2}-0.4034 Q+2.0314
$$

This linear regression model presented on Eq. (21) have a determination coefficient of $\mathrm{R}^{2}=0.9976$. Through the use of the linear regression model to calculate the relative velocity coefficient $(\alpha)$ for isothermal laminar Newtonian flows, a value of $\alpha=2.0314$ was obtained. Thus, this velocity coefficient value is very close to the $\alpha=2$ value, which is calculated theoretically.

In order to validate the proposed fluid-dynamics model for non-isothermal Newtonian flows, an experimental dimensionless velocity profile was evaluated for $\mathrm{Q}=-1.35$ (Kwant, Fierens, Van Der Lee, 1973a). A good agreement was observed between the dimensionless velocity profile (obtained from the proposed fluid-dynamics model) regarding experimental data. This evaluation was presented on Fig. 4.

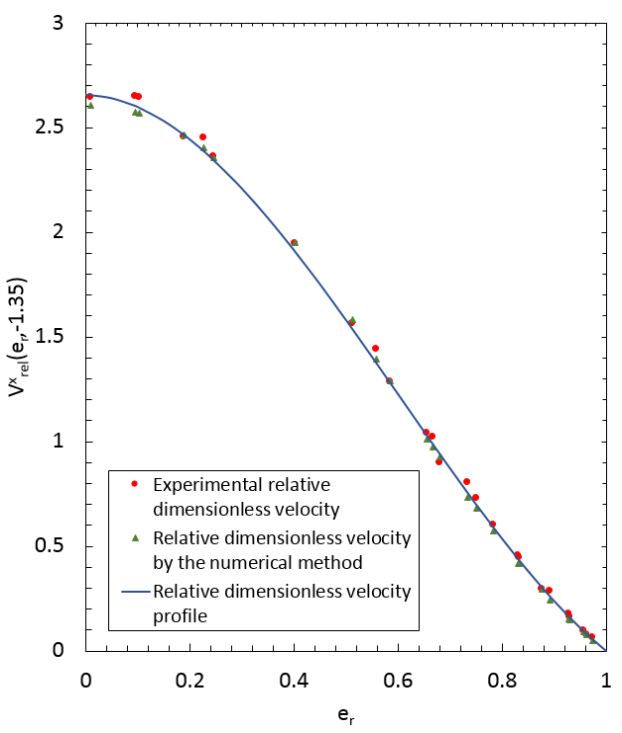

Figure 4. Dimensionless velocity profile for $\mathrm{Q}=$ 1.35 .

Through the use of Eq. (21), a value of $\alpha=2.655$ was calculated. The RMS error for data obtained from the proposed model (using Eq. (21) to calculate the relative velocity coefficient) was equivalent to 0.03169, and the RMS error from data obtained through the numerical method was equivalent to 0.03817 . 


\section{CONCLUSIONS}

It can be concluded from the results that dimensionless velocity profiles obtained for the proposed fluid-dynamics model efficiently calculate experimental dimensionless velocities for nonisothermal Newtonian flows. Dimensionless velocity profiles obtained through the use of the fluiddynamics model are better to model dimensionless velocity profiles in cooling processes, in comparison to dimensionless velocity profiles in heating processes, for which heating is even higher in the flow. Due to the flexibility to which the variables might depend, or how the relative velocity coefficient ( $\alpha$ ) can be defined, it is possible to employ the proposed fluid-dynamics model in future studies to obtain velocity profiles for non-Newtonian flows.

\section{REFERENCES}

Alba, K., and Frigaard, I. A., 2016, Dynamics of the Removal of Viscoplastic Fluids from Inclined Pipes, Journal of Non-Newtonian Fluid Mechanics, Vol. 229, pp. 43-58.

Amaro, J., Hernández, O., and Olivencia, J., 2015, Cálculo del Campo de Velocidad de un Flujo Laminar de Agua al Interior de una Tubería, Enfriándose con el Medio Ambiente Después del Completo Desarrollo Hidrodinámico, Agroindustrial Science, Vol. 5, pp. 127-132. (in Spanish)

Ancey, C., and Bates, B. M., 2017, Stokes' Third Problem for Herschel-Bulkley Fluids, Journal of Non-Newtonian Fluid Mechanics, Vol. 243, pp. 27-37.

Bentrad, H., Esmael, A., Nouar, C., Lefevre, A., and Ait-Messaoudene, N., 2017, Energy Growth in Hagen-Poiseuille Flow of Herschel-Bulkley Fluid, Journal of Non-Newtonian Fluid Mechanics, Vol. 241, pp. 43-59.

Bertsche, D., Knipper, P., and Wetzel, T., 2016, Experimental Investigation on Heat Transfer in Laminar, Transitional and Turbulent Circular Pipe Flow, International Journal of Heat and Mass Transfer, Vol. 95, pp. 1008-1018.

Choi, M. K., Cho, M. K., Lee, H. W, Jung, H., and Lee J. W., 2016, Generalized Equation for the Design of a Baffle to Generate Arbitrary Flow Velocity Profiles, Journal of Wind Engineering and Industrial Aerodynamics, Vol. 149, pp. 30-34.

Devore, J. L., and Berk, K. N., 2012, Modern Mathematical Statistics with Applications, Springer Book.

Güzel, B., Frigaard, I., and Martinez, D. M., 2009, Predicting Laminar-Turbulent Transition in Poiseuille Pipe Flow for Non-Newtonian Fluids, Chemical Engineering Science, Vol. 64, pp. 254-264.

Hanley, K. J., Cronin, K., and Byrne, E. P., 2013, Dispersion in Particle Velocity Resulting from Random Motion through a Spatially-Varying Fluid Velocity Field in a Pipe, Powder Technology, Vol.
245 , pp. 255-264.

Irgens, F., 2014, Rheology and Non-Newtonian Fluids, Springer Book.

Kim, D. H., Lee, B. J., Park, J. S., Kwak, J. S., and Chung, J. T., 2016, Effects of inlet Velocity Profile on Flow and Heat Transfer in the Entrance Region of a Ribbed Channel, International Journal of Heat and Mass Transfer, Vol. 92, pp. 838-849.

Kleijnen, J. P. C., 2015, Design and Analysis of Simulation Experiments, Springer Book.

Kwant, P. B., 1971, Non-Isothermal Laminar Flow, Doctoral Thesis, Delft University of Technology.

Kwant, P. B., Fierens, R. H. E., and Van der lee, A., 1973a, Non-Isothermal Laminar Pipe Flow - II. Experimental, Chemical Engineering Science, Vol. 28, pp. 1317-1330.

Kwant, P. B., Zwaneveld, A., and Dijkstra, F. C., 1973b, Non-Isothermal Laminar Pipe Flow - I. Theoretical, Chemical Engineering Science, Vol. 28, pp. 1303-1316.

López-carranza, S. N., Jenny, M., and Nouar, C., 2012, Pipe Flow of Shear-Thinning Fluids, Comptes Rendus - Mecanique, Vol. 340, pp. 602618.

Martins, N. M. C., Carriço, N. J. G., Ramos H. M., and Covas, D. I. C., 2014, Velocity-Distribution in Pressurized Pipe Flow Using CFD: Accuracy and Mesh Analysis, Computers and Fluids, Vol. 105, pp. 218-230.

Martins, N. M. C., Soares, A. K., Ramos, H. M., and Covas, D. I. C., 2016, CFD Modeling of Transient Flow in Pressurized Pipes, Computers and Fluids, Vol. 126, pp. 129-140.

Peixinho, J., Nouar, C., and Desaubry, C., Théron, B., 2005, Laminar Transitional and Turbulent Flow of Yield Stress Fluid in a Pipe, Journal of Non-Newtonian Fluid Mechanics, Vol. 128, pp. 172-184.

Tu, W., Tang, Y., Hu, J., Wang, Q., and Lu, L., 2015, Heat Transfer and Friction Characteristics of Laminar Flow through a Circular Tube with Small Pipe Inserts, International Journal of Thermal Sciences, Vol. 96, pp. 94-101.

Wang, J., Wang, S., Zhang, T., and Battaglia, F., 2017, Mathematical and Experimental Investigation on Pressure Drop of Heterogeneous Ice Slurry Flow in Horizontal Pipes, International Journal of Heat and Mass Transfer, Vol. 108, pp. 2381-2392.

Wang, J., Zhang, T., and Wang, S., 2013, Heterogeneous Ice Slurry Flow and Concentration Distribution in Horizontal Pipes, International Journal of Heat and Fluid Flow, Vol. 44, pp. 425-434.

Weigand, B., and Abdelmoula, M., 2014, Axial Heat Conduction Effects in the Entrance Region of Laminar Duct Flows: Correlations for the Local Nusselt Number, International Communications in Heat and Mass Transfer, Vol. 51, pp. 45-50. 